\title{
Quelques aspects du contact culturel dans la région du détroit de Belle Isle (Canada)
}

Louis-Jacques Dorais et Valérie Céré

\section{OpenEdition}

1 Journals

Édition électronique

URL : https://journals.openedition.org/jsa/12368

DOI : 10.4000/jsa. 12368

ISSN : $1957-7842$

Éditeur

Société des américanistes

Édition imprimée

Date de publication : 31 décembre 2012

Pagination : 141-166

ISSN : 0037-9174

\section{Référence électronique}

Louis-Jacques Dorais et Valérie Céré, «Quelques aspects du contact culturel dans la région du détroit de Belle Isle (Canada) », Journal de la Société des américanistes [En ligne], 98-2 | 2012, mis en ligne le 10 décembre 2015, consulté le 04 septembre 2022. URL : http://journals.openedition.org/jsa/ 12368 ; DOI : https://doi.org/10.4000/jsa.12368 


\title{
QUELQUES ASPECTS DU CONTACT CULTUREL DANS LA RÉGION DU DÉTROIT DE BELLE ISLE (CANADA)
}

\author{
Louis-Jacques DORAIS et Valérie CÉRÉ *
}

Fondé à la fois sur des données de terrain et une analyse des publications disponibles, cet article décrit certains aspects de la culture mixte inuit-européenne qui s'est développée dans la région du détroit de Belle Isle (Canada oriental) à partir du XVIII ${ }^{\mathrm{e}}$ siècle. Nous nous intéressons au complexe de l'attelage de chiens, emprunté à la technologie inuit, qui constitue un excellent exemple de métissage culturel. Nous chercherons à montrer comment ce genre de trait culturel d'origine autochtone peut renforcer les revendications territoriales des habitants de la région, dont plusieurs ont des ancêtres inuit. [Mots-clés : métissage, revendications autochtones, Labrador, Inuit, traîneau à chiens.]

Some aspects of cultural cross-breeding in the Belle Isle Strait region. This article, based on field work and on an analysis of published literature, describes a number of aspects of the mixed Inuit-European culture that has developed in the Belle Isle Strait region (eastern Canada) since the 18th century. The dog-team complex, borrowed from Inuit technology, is discussed in a more thorough way, because it constitutes an excellent example of cultural cross-breeding. The article aims at showing how this type of aboriginal cultural traits can strengthen the land claims of the local people, many of which have Inuit ancestors. [Key words : cross-breeding, aboriginal claims, Labrador, Inuit, dog sled.]

Algunos aspectos del mestizaje cultural en la región del estrecho de Belle Isle. Este artículo, que está basado tanto en entrevistas de campo como en el análisis de las publicaciones disponibles, describe ciertos aspectos de la cultura mixta inuit-europea que se desarrolló en la región del estrecho de Belle Isle (Canadá oriental) a partir del siglo XVIII. Nos interesamos particularmente por el arte del tiro de perros, apropiado de la tecnología inuit, que constituye un excelente ejemplo de mestizaje cultural. El artículo busca mostrar cómo este tipo de rasgo cultural de origen indígena puede reforzar las reivindicaciones territoriales de los habitantes de la región, entre los cuales varios tienen ancestros inuit. [Palabras claves : mestizaje, reivindicaciones indígenas, Labrador, inuit, trineo de perros.]

* Département d'anthropologie, université Laval, Québec, Canada G1V 0A6

[louis-jacques.dorais@ant.ulaval.ca ; vcere@hotmail.com].

Journal de la Société des Américanistes, 2012, 98-2, pp. 141-166. C Société des Américanistes. 


\section{INTRODUCTION}

Séparant l'île de Terre-Neuve de la côte septentrionale du golfe du SaintLaurent et unissant ce dernier à l'océan Atlantique, le détroit de Belle Isle est l'un des tout premiers points de contact entre populations autochtones et Européens au nord-est de l'Amérique du Nord. C'est sur sa rive sud, à l'Anse aux Meadows, qu'on a découvert le seul site norrois (c'est-à-dire viking) attesté du continent nord-américain. Depuis le début du $\mathrm{XVI}^{\mathrm{e}}$ siècle, le détroit a été visité de façon récurrente par des pêcheurs, baleiniers et trafiquants portugais, basques, bretons, français et britanniques, avant que ne s'y fixe un peuplement sédentaire d'origine européenne, à partir de 1820. Et pendant tout ce temps, la région était fréquentée par des Amérindiens innuat de langue algonquienne et des Inuit ${ }^{1}$ venus du nord.

Les contacts entre allochtones et populations inuit, qui nous intéressent ici, se sont étendus à l'ensemble du Labrador (côte de l'océan Atlantique) ainsi qu'à la Basse-Côte-Nord du golfe du Saint-Laurent, au sud-ouest du détroit de Belle Isle. $\mathrm{Si}$, dans la moitié nord de la région, la culture et la langue inuit se sont perpétuées jusqu'à nos jours, il n'en est pas de même dans sa partie sud et dans les territoires adjacents (Figure 1), où les contacts entre indigènes et pêcheurs anglo-saxons ont plutôt entraîné l'émergence d'une population de langue anglaise, biologiquement et culturellement mixte (les Settlers ou Liveyeres), qui se définit aujourd'hui comme métisse et revendique à ce titre des droits territoriaux autochtones. L'anthropologue Charest (2007, p. 63, 2008, p. 24) a qualifié de «sous-aire culturelle du Labrador méridional » la zone où prédomine le mode de vie propre aux habitants de ces contrées.

Les principaux traits distinctifs de ce mode de vie ont déjà fait l'objet d'un certain nombre de descriptions (voir, par exemple, Junek 1937 ; Breton 1968 ; Charest 1976, 1998, 2007, 2008 ; Borlase 1994 ; Kennedy 1995, 1996a). Cependant, les origines autochtones de quelques-uns de ces traits, quoique souvent signalées, n'ont jamais été systématiquement comparées avec leurs équivalents inuit $^{2}$. C'est une telle comparaison que nous voulons esquisser dans ce texte, en nous concentrant plus particulièrement sur le complexe du traîneau et de l'attelage de chiens. Notre description prendra appui sur les données recueillies dans la zone du détroit de Belle Isle prise au sens large ${ }^{3}$, mais pas uniquement puisque ce complexe se retrouve ailleurs dans la région. Dans les pages qui suivent, nous retracerons d'abord la genèse d'une culture métisse au Labrador méridional ${ }^{4}$, en mettant l'accent sur les éléments d'origine inuit faisant partie de cette culture et sur le rôle que de tels traits culturels autochtones peuvent jouer dans les revendications territoriales des métis labradoriens d'aujourd'hui, avant de décrire l'attelage canin, en tant qu'exemple probant de ce métissage culturel. 


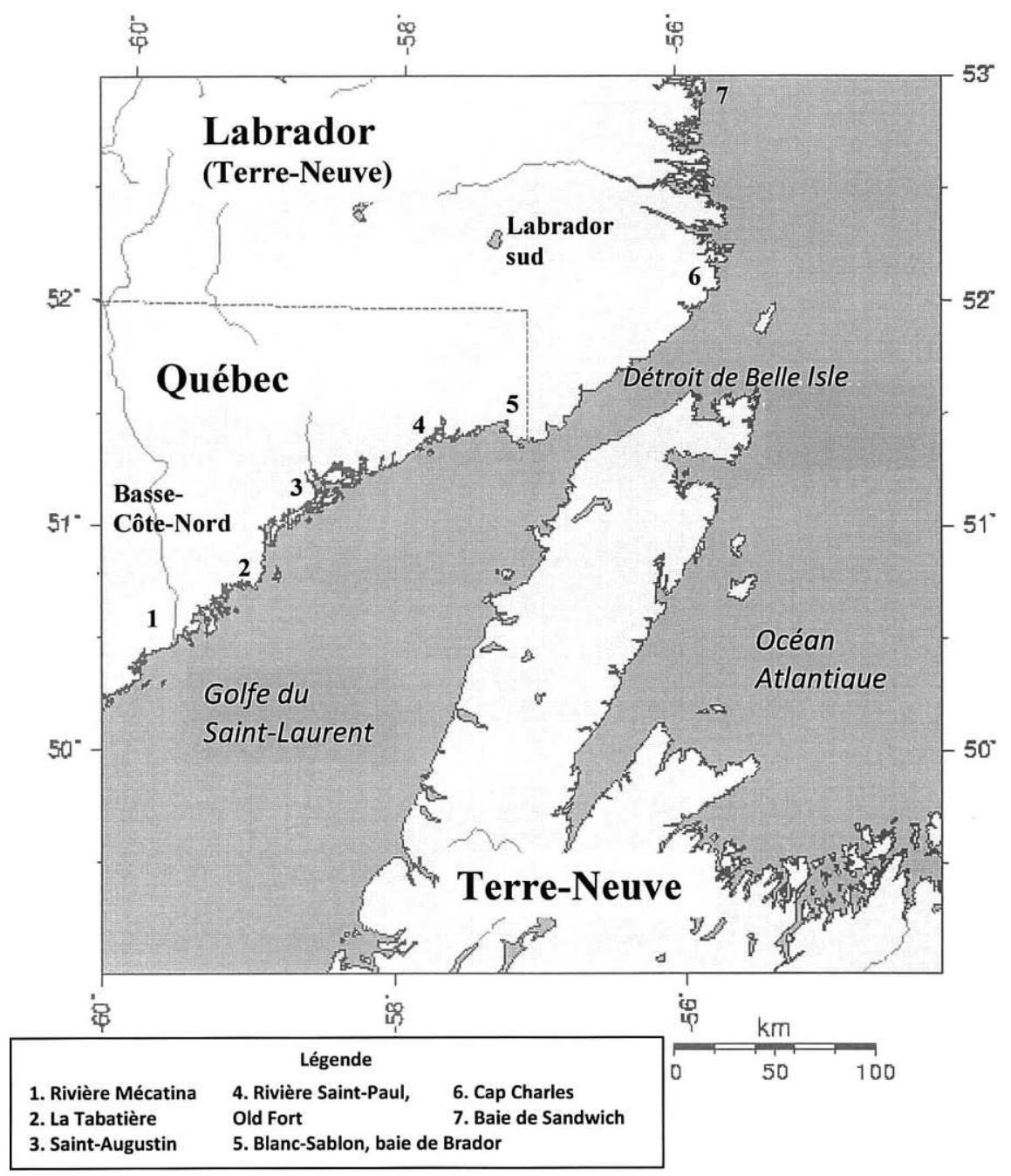

FIG. 1 - Le Labrador méridional.

\section{LES CONTACTS ENTRE INUIT ET EUROPÉENS AU LABRADOR MÉRIDIONAL}

L'épisode norrois de la fin du $\mathrm{X}^{\mathrm{e}}$ siècle mis à part, les Européens commencèrent à fréquenter le détroit de Belle Isle à partir du tournant $d u \mathrm{XVI}^{\mathrm{e}}$ siècle. Ils venaient principalement pour pêcher la morue, pour chasser la baleine et le loup-marin ${ }^{5}$ dans les eaux environnant les côtes du détroit, le sud du Labrador et l'île de 
Terre-Neuve. Dès les tout débuts, ils entrèrent en relation avec les populations amérindiennes (les Innuat, naguère connus sous le nom de Montagnais, et peutêtre aussi les Beothuk) qui fréquentaient la région pour les mêmes raisons qu'eux. Un peu plus tard, quand ils remontèrent le long de la côte méridionale du Labrador, les Européens rencontrèrent des groupes inuit. Dès 1542, le pilote Jean Alfonse décrit des " gens qui ont queuhes et visages de porceaulx... et font leurs maisons dessoubz la terre et les doublent de tables de sappins et d'autre choses ${ }^{6}$... ils sont vestuz de peaux » (in Martijn 1980, p. 106). Une affiche imprimée en Allemagne en 1566 informe le public de l'exhibition dans les foires d'une « femme sauvage et [de] sa petite fille » capturées à Nova Terra (les côtes de Terre-Neuve et du Labrador fréquentées par les pêcheurs européens); «toutes deux portent le vêtement inuit caractéristique : parka à capuchon, pantalon et hautes bottes. La femme a en outre le menton tatoué » (ibid., p. 107).

Après 1550, semble-t-il, les Inuit du nord prirent l'habitude de descendre vers le détroit en été et en automne pour y faire la traite avec les Européens. Mais les relations s'envenimèrent rapidement. En 1588, à Quirpon (rive sud du détroit), un matelot embarqué sur un navire malouin tira sur les occupants d'un campement autochtone, tuant une femme (ibid.). Cet incident déclencha des hostilités qui allaient se poursuivre pendant près de deux siècles. Se méfiant des pêcheurs et chasseurs étrangers, les Inuit prirent l'habitude de les harceler pour leur voler leurs barques et leurs outils de métal ${ }^{7}$, profitant souvent de leur hivernage en Europe pour dérober ce qu'ils laissaient sur place (Trudel 1980). Quelques familles inuit s'installèrent alors de façon permanente à Blanc-Sablon et dans les zones environnantes (à la rivière Saint-Paul en particulier) pour y chasser le loupmarin en migration et y poursuivre leurs rapines, seul moyen de se procurer des biens européens après 1660, date à partir de laquelle les pêcheurs refusèrent carrément de commercer avec eux ${ }^{8}$.

À la fin $\mathrm{du} \mathrm{XVII}^{\mathrm{e}}$ siècle, la couronne française concéda la région du détroit de Belle Isle et certaines zones de la Basse-Côte-Nord et du Labrador sud à des personnes qui obtenaient le droit exclusif d'y exploiter des pêcheries et de faire la traite avec les autochtones. Si les relations avec les Innuat, alliés de la France et vivant surtout à l'intérieur des terres, ne posaient pas problème, les rapports avec les Inuit ne s'améliorèrent pas, malgré des tentatives pour reprendre contact (expéditions françaises le long de la côte Atlantique du Labrador). En 1705, un fort français fut établi à la baie de Brador, pour bloquer l'expansion des Inuit vers le sud-ouest. La dernière mention d'hivernage inuit sur la Basse-Côte-Nord (deux familles), à l'embouchure de la rivière Mécatina, date de 1729 (Martijn 1980). Mais les rapports n'en furent pas complètement coupés pour autant, comme en témoigne l'existence au cours du $\mathrm{XVIII}^{\mathrm{e}}$ siècle de relations commerciales sporadiques qui donnèrent même naissance à une langue de traite mixte (un pidgin) composée de mots français, inuit, basques et innuat ${ }^{9}$, en usage au détroit de Belle Isle et dans les zones environnantes (Dorais 1980 ; van der Voort 1994). 
La conquête du Canada par les Britanniques (1760) allait changer la donne. En 1765, le gouverneur de Terre-Neuve, Hugh Palliser, signa une trêve avec les Inuit à la baie des Châteaux, aux environs du cap Charles. Des protestants d'origine allemande, les Frères Moraves, obtinrent la permission d'établir des missions et des postes de traite dans la moitié nord du Labrador, ce qui entraîna le retrait de la plupart des Inuit qui fréquentaient le sud de la région ${ }^{10}$. Le Labrador méridional fut affermé à des intérêts anglais et jersiais détenant en principe le monopole de la pêche à la morue et au loup-marin ${ }^{11}$, et seuls les engagés des compagnies fermières avaient le droit d'y résider.

Malgré le repli des Inuit vers le nord, quelques familles continuèrent à fréquenter la région pour y pratiquer la chasse et la pêche - certains hommes ont peut-être travaillé pour les compagnies fermières ${ }^{12}$ - et, sans doute aussi, pour y commercer avec les Européens. Dès 1798, des Inuit qui, d'après certains, vivaient dans les environs venaient traiter à Battle Harbour (près du cap Charles). Il s'agit de Shilmuck (Sirmiq ?), Eteweook (Itiviuq ?) et Oglucock (Aglukak) (Kennedy 1995, p. 84). Durant l'été 1817, 50 autochtones campaient à l'Anse-au-Loup (à l'est de Blanc-Sablon), sans toutefois y résider en permanence (Dorais 1980, p. 3).

\section{GENÈSE D'UNE CULTURE MÉTISSE}

Jusqu'en 1820, le Labrador méridional resta interdit au peuplement permanent. Les contacts entre Inuit et Européens étaient donc passagers, sauf rares exceptions. Il y eut quand même un certain nombre d'emprunts d'une culture à l'autre. Comme on l'a signalé, les Inuit se procurèrent assez tôt des barques de type européen et, tant au sud qu'au nord du Labrador, ils adoptèrent bon nombre de techniques de chasse, de pêche et de piégeage d'origine française ou britannique, entre 1765 et 1835 en particulier (Clermont 1980, p. 164). Inversement, les Européens fréquentant le détroit de Belle Isle et les régions environnantes empruntèrent quelques éléments de culture matérielle autochtone comme les raquettes à neige et le canot d'écorce innuat, ou certaines pièces de vêtement inuit (les bottes en peau de loup-marin par exemple ${ }^{13}$ ), afin de faciliter leur adaptation au milieu.

Mais c'est après 1820 qu'allait voir le jour la culture métisse du Labrador méridional telle que définie par Charest (2007). Cette année-là, en effet, le gouvernement britannique mit fin au monopole des compagnies et ouvrit le territoire au libre peuplement. D'anciens employés des postes de pêche affermés, souvent originaires des îles britanniques, rachetèrent certains de ces postes et y firent venir leur famille. Des pêcheurs anglophones de l'île de Terre-Neuve s'installèrent des deux côtés de la frontière Québec-Labrador ${ }^{14}$, entre la baie de Sandwich au nord et Kegaska au sud-ouest (à $120 \mathrm{~km}$ au-delà de la rivière Mécatina), alors qu'un petit nombre de francophones venus de la vallée du 
Saint-Laurent fondèrent trois établissements, du côté québécois de la frontière ${ }^{15}$. On peut présumer que les savoirs accumulés par les anciens employés des compagnies de pêche et de traite, y compris les quelques traits de culture autochtone qu'ils avaient adoptés, furent transmis aux nouveaux arrivants, puisqu'ils étaient garants d'une adaptation réussie à un milieu naturel exigeant.

Les apports culturels indigènes allaient reprendre de la vigueur avec l'arrivée, après 1820 , de familles inuit venues du nord. Attirées par les pêcheries, celles-ci s'installèrent tant au Labrador sud qu'au détroit de Belle Isle et sur la Basse-CôteNord. Comme près de $90 \%$ des arrivants terre-neuviens étaient des hommes, plusieurs épousèrent des femmes inuit, engendrant ainsi une population en partie métissée. Au Labrador sud, dès les années 1840, on signale la présence en quelques endroits d'Inuit et de leurs descendants métis qui ne parlent plus leur langue d'origine, l'inuktitut, et ont abandonné les pratiques chamaniques (Kennedy 1995, p. 85). Autochtones et pêcheurs d'origine européenne se sont donc partiellement fondus ensemble, les premiers adoptant la langue anglaise et le christianisme. Jusqu'au début du $\mathrm{xx}^{\mathrm{e}}$ siècle, on rencontrait toutefois au Labrador sud quelques Inuit moins métissés, comme cette Nancy Williams de la baie de Sandwich, qu'un visiteur de 1915 qualifiait de "pure-bred Eskimo » ( « Esquimaude de race pure ») ou, encore, Betsy Paulo (ou Pawlo ${ }^{16}$ ), décédée en 1921 aux environs du cap Charles, dont on se souvenait, soixante ans plus tard, qu'elle connaissait l'inuktitut (Kennedy 1996b). En raison de cet apport autochtone, 17 villages du sud du Labrador abritaient des résidents d'ascendance inuit en $2006^{17}$.

$\mathrm{Au}$ détroit de Belle Isle, on rapportait en 1854 que les Inuit de la région s'étaient complètement assimilés aux Européens, à ceci près qu'un ou deux hommes utilisaient encore le kayak. On signalait également en 1860 qu'une famille inuit et un couple mixte (l'épouse était autochtone) habitaient une île du détroit, Caribou Island (Dorais 1980, p. 3). Dans un entretien avec Céré (2012), en février $2011^{18}$, un résident d'Old Fort lui a expliqué que, s'il comptait des ancêtres inuit, c'est que des pêcheurs anglophones (Settlers) du Labrador sud avaient d'abord épousé des autochtones et que certains de leurs descendants métis étaient ensuite venus s'installer au détroit de Belle Isle où ils avaient pris époux ou épouse dans la population locale. Les aînés dont il gardait le souvenir n'avaient, à sa connaissance, jamais rencontré d'Inuit dans la région. En revanche, ils avaient souvent été en contact avec les Innuat de Pakuashipi (à côté de Saint-Augustin), qui descendaient occasionnellement jusqu'au détroit. Cet informateur mentionnait toutefois que, si son ascendance et celle de ses concitoyens étaient partiellement inuit, aucun d'entre eux ne possédait d'ancêtres amérindiens.

À Saint-Augustin, la présence d'Inuit est signalée en 1858 et 1868, et deux ou trois femmes appartenant à ce groupe ont épousé des anglophones entre 1840 et 1870 (Tremblay, Charest et Breton 1969). Dans un article très fouillé, Charest (1998) a retracé l'ascendance inuit des habitants de la Basse-Côte-Nord ${ }^{19}$ 
dans son ensemble. Ses recherches montrent que, vers 1850, trois familles complètement ou partiellement inuit (douze personnes environ) étaient établies dans la région. Elles représentaient 3,5\% de la population totale, estimée alors à 350 personnes (ibid., pp. 10-11). Ces entités familiales étaient les suivantes: 1) à Saint-Augustin, la famille de Louis l'Esquimau et de sa femme Marie, dont on disait qu'ils « savaient bien la langue anglaise » (ibid.) ; 2) à Saint-Augustin aussi, le couple formé par Andrew Kennedy (un allochtone) et Catherine Wilshire (une Inuk) ; 3) à la rivière Saint-Paul, George Dukes (qui n'était probablement pas autochtone) et sa femme Jenny Menouque (Manuk).

Tous ces couples étaient originaires du Labrador ${ }^{20}$ et tous ont laissé des descendants sur la Basse-Côte-Nord. En se fondant sur des données recueillies entre 1965 et 1968, Charest (ibid., p. 23) estime qu'à cette époque, 784 personnes de la région avaient au moins un ancêtre inuit, soit 17,6 \% d'une population totale de 4463 habitants. Au milieu des années 1960, 12 des 14 villages de la Basse-CôteNord comptaient des résidents d'ascendance inuit, mais ceux-ci se répartissaient inégalement. Particulièrement nombreux à Saint-Augustin $(49 \%$ de la population) et à Old Fort (36\%), ils formaient des minorités importantes (de 15 à $26 \%$ ) à Blanc-Sablon, La Tabatière et rivière Saint-Paul. À cette époque, on connaissait l'ascendance inuit de certaines familles (les Shattler, les Goddard et les Léon par exemple) et on préservait le souvenir de Jenny Menouque et de sa petite-fille Lucy Dukes, mais, en raison de la complexité des liens généalogiques, on ne mesurait pas toute l'ampleur du phénomène (ibid., p. 25) ${ }^{21}$. En extrapolant à partir des données statistiques de Charest (1998) et de celles de la Labrador Metis Nation (www.labradormetis.ca), on peut estimer à environ 6000 personnes (sur un total de 10 000) les habitants de la Basse-Côte-Nord, du détroit de Belleîle et du Labrador sud qui comptaient au moins un ascendant inuit en $2006^{22}$.

Au-delà des croisements biologiques, les résidents de la région ont développé, depuis le début du $\mathrm{XIX}^{\mathrm{e}}$ siècle, une culture métisse incluant à la fois des traits européens et des caractères autochtones (innuat et, surtout, inuit), qui est partagée par tous quelle que soit leur ascendance. Fruit de conditions historiques particulières, cette culture possède huit traits marquants dont la combinaison spécifique assure son originalité (Charest 2007, p. 66 ; 2008, p. 24) ${ }^{23}$. Comme on l'a déjà mentionné, Charest $(2007$, p. 63) estime ainsi possible de définir une « sous-aire culturelle du Labrador méridional ». Celle-ci se distingue de toutes ses voisines - aires ou sous-aires du Labrador central et septentrional, de l'île de TerreNeuve et de la Moyenne-Côte-Nord du golfe du Saint-Laurent - par la façon dont elle combine les huit traits et par le fait que ceux-ci ne sont pas partout présents ${ }^{24}$.

\section{UNE IDENTITÉ AUTOCHTONE}

Ces croisements biologiques et cette culture régionale, dont nous allons décrire le contenu d'origine inuit dans la suite de ces pages, ont récemment mené 
une partie de la population de la région à revendiquer une identité autochtone. Pendant longtemps, les racines partiellement indigènes des Liveyeres et des Settlers avaient été mises sous le boisseau. Les Inuit (et les Amérindiens) étaient généralement méprisés, faisant l'objet de moqueries et de discrimination, et les métis préféraient souvent cacher leurs origines ${ }^{25}$. Outre certains éléments de culture matérielle, c'est plutôt dans les gestes quotidiens qu'on pouvait (et peut encore) observer des traits culturels métis : méthodes d'orientation en mer et sur terre, appropriation et utilisation du territoire, lien avec la nature, etc.

Les choses commencèrent à changer au cours des années 1970, quand le gouvernement canadien fut forcé par un jugement de la Cour suprême - le jugement Calder (1973) - de reconnaître l'existence d'un titre juridique autochtone ${ }^{26}$. L'ascendance indigène ouvrait donc désormais la voie à la reconnaissance éventuelle de droits collectifs sur l'exploitation et la gestion du territoire occupé ${ }^{27}$. En ce qui concerne les populations métisses - c'est-à-dire sans statut amérindien ou inuit légalement défini - une décision rendue par la Cour suprême du Canada en 2003, le jugement Powley, reconnaît qu'elles peuvent jouir de droits territoriaux à certaines conditions (ancienneté du métissage, identité communautaire qui leur est propre, etc.). L'une de ces conditions est d'ordre culturel (Rousseau et Rivard 2007, p. 3) :

Une communauté métisse, en regard du jugement, est un groupe composé de membres aux origines mixtes ayant développé sur un territoire donné leurs "propres coutumes, façons de vivre et identité collective reconnaissables et distinctes de celles de leurs ancêtres indiens ou inuit d'une part » et de leurs ancêtres européens d'autre part (R. c. Powley 2003, § 10).

Les métis inuit du Labrador n'ont pas attendu le jugement Powley pour proclamer leur identité autochtone. Au Labrador septentrional, dès le milieu des années 1970, les métis locaux (Qallunaangajuit) furent invités à se joindre à la Labrador Inuit Association (LIA), qui entamait la négociation des droits territoriaux inuit. Dix ans plus tard, la même invitation fut lancée aux Settlers du Labrador central. En 2005, la LIA signait avec les gouvernements de Terre-Neuve et du Canada une entente qui reconnaissait aux Inuit et métis de la région des droits territoriaux et une autonomie politique partielle dans la moitié nord du Labrador (le Nunatsiavut, « notre beau territoire ») ${ }^{28}$.

$\mathrm{Au}$ Labrador sud, sans population explicitement reconnue comme inuit, des métis fondaient en 1986 la Labrador Metis Association, devenue plus tard la Labrador Metis Nation, et commençaient à se désigner sous le nom de Metis plutôt que sous ceux de Settlers ou Liveyeres, comme cela avait été le cas jusque-là (Kennedy 1996b). Ils purent ainsi avoir accès à des subsides fédéraux destinés aux autochtones et, en 1991, l'association déposait à Ottawa une demande de reconnaissance des territoires traditionnellement occupés et exploités par les métis inuit, le NunatuKavut («nos anciennes terres» en inuktitut ${ }^{29}$ ). 
L'appartenance à la Labrador Metis Nation est ouverte à tout Inuk ou métis inuit qui n'a pas légalement le droit de faire partie d'un autre organisme autochtone et qui habite le Labrador depuis au moins six mois. Il existe aussi un statut de membre non résident, réservé aux Inuit et métis inuit qui soutiennent les objectifs de la Nation, mais vivent habituellement hors du Labrador (www.labradormetis.ca).

Dans la partie québécoise du détroit de Belle Isle ainsi que sur la Basse-CôteNord, il n'existe pas encore de structure équivalente à la Labrador Metis Nation, mais des métis de Saint-Augustin ont fondé en 2000 l'association Nunamit (« en provenance du territoire $»)$, afin de faire connaître leur existence ${ }^{30}$. Certains sont membres non résidents de l'organisme labradorien. De plus, l'Alliance autochtone du Québec, une association pan-québécoise défendant les droits des métis, a commandé une étude sur la communauté de Saint-Augustin (Charest 2005). De façon générale, des gens qui, jusqu'à récemment, avaient tendance à taire leurs origines autochtones clament maintenant publiquement leur ascendance inuit.

\section{Traits CULTURELS D'ORIGINE INUIT}

Cette ascendance se double, comme on l'a vu, d'un fonds culturel partiellement inuit. Au Labrador méridional, celui-ci se rattache surtout aux premier et second traits de la nomenclature proposée par Charest $(2008$, p. 24) pour caractériser la culture métisse de la région : l'adaptation au milieu et l'héritage culturel autochtone. Pour survivre dans un environnement côtier difficile, caractérisé par la mobilité spatiale des habitants (transhumance liée aux ressources à exploiter à chaque saison), par la multiplicité des activités de production (pêche, chasse, piégeage, cueillette, coupe du bois) et par la faible densité de population (vers 1850, un millier de personnes réparties sur $800 \mathrm{~km}$ de côte), les pionniers allochtones et métis ont dû adopter plusieurs techniques et autres traits culturels d'origine inuit ${ }^{31}$ (Charest 2007, p. 67). Les traits les plus souvent évoqués sont : " la chasse au loup-marin, le traîneau à chiens, les vêtements en peau de loup-marin, des outils comme le harpon et le ulu [ou uluk] (couteau [principalement utilisé par les] femme[s] en forme de demi-lune [inconnu sur la Basse-Côte-Nord]). On pourrait ajouter le cycle annuel d'activités diversifiées et la mobilité spatiale qui en est une conséquence [...]» (ibid.).

Cet héritage culturel s'est probablement transmis par deux voies, liées aux savoir-faire propres à chaque sexe : par l'entremise des épouses autochtones de certains pionniers (vêtements et bottes en loup-marin) et par celle des quelques hommes inuit établis dans la région (techniques de chasse, traîneau et attelage, fabrication d'outils). Il s'est ensuite perpétué grâce à la tradition orale. On peut envisager une diffusion allant du nord-est vers le sud-ouest, à partir du Labrador 
septentrional et central, en passant par le Labrador sud, jusqu'à la Basse, puis à la Moyenne-Côte-Nord (pour un nombre limité de traits en ce qui concerne cette dernière).

Les chercheurs qui, comme Charest et, plus récemment, Céré (2012), ont travaillé dans des communautés métisses du Labrador et de la Basse-Côte-Nord, ont tous observé les apports inuit à la culture locale ou, du moins, ce qu'il en subsiste aujourd'hui. Au Labrador septentrional, où métis et autochtones se partagent toujours le territoire, le mode de vie des uns et des autres offre beaucoup de similitudes. La description de ces points de convergence, tels qu'ils ont été étudiés par l'anthropologue Ben-Dor (1966) en 1962-1963, offre un exemple intéressant de ce à quoi pouvait ressembler la culture matérielle du Labrador méridional au XIX ${ }^{\mathrm{e}}$ siècle et dans le premier tiers $\mathrm{du} \mathrm{Xx}^{\mathrm{e}}$ siècle $^{32}$ :

Les ressemblances entre Settlers [métis anglophones ${ }^{33}$ ] et Esquimaux sont frappantes pour ce qui est de la culture matérielle. Celui qui rend occasionnellement visite à un foyer settler pourrait trouver le chef de famille en train de dépecer un phoque, sa femme en train de fabriquer une paire de bottes de peau en mâchant les rebords d'une peau prédécoupée, là où elle disposera des points de couture imperméables, et un fils en train de construire un nouveau kamotik, un traîneau à chiens, en fixant les barres transversales aux patins avec des lanières en cuir de phoque. (Ben-Dor 1966, p. 31 ; traduction des auteurs)

Ben-Dor (ibid., pp. 32-37) donne une liste des éléments de culture matérielle empruntés aux Inuit par les Settlers, ainsi que des noms d'origine autochtone de certains d'entre eux :

le traîneau (kamotik; inuktitut qamutiik) et l'attelage de chiens ;

la parka à capuchon en deux couches (interne et externe) appelée dickey (atigik en inuktitut) [à l'époque de Ben-Dor, elle est faite de tissu acheté au magasin et non plus en peau de phoque] ;

les moufles en peau de phoque ;

les bottes imperméables en peau de phoque rasée (kamik);

le couteau féminin en demi-lune (uluk);

les outils pour étirer les bottes séchées ou rétrécies : le kilyutik (qauliutik) et le tisikut (tasikqutik);

le grattoir à peau (kiliutak);

le harpon (unak; inuktitut unaak) à tête détachable (naulak).

Ben-Dor mentionne également deux éléments importants de la culture matérielle inuit que les Settlers n'ont pas empruntés : le kayak et la maison de neige ${ }^{34}$.

L'anthropologue Zimmerly (1975, p. 72), qui a travaillé au Labrador central (région adjacente à celle qui nous intéresse ici) au début des années 1970, fait les mêmes constatations que Ben-Dor (ibid.) : 
Ces savoir-faire et ces outils, tel l'ulu ou couteau en forme de croissant des femmes esquimaudes, l'usage de celui-ci pour gratter les peaux de phoque ${ }^{35}$, le kamutik (traîneau à chiens esquimau), le harpon pour capturer les phoques à leur trou de respiration sur la glace, et la parka esquimaude fabriquée sur mesure, bordée de fourrure et qu'on enfile par dessus la tête (appelée dickie par les Settlers), tous ces éléments, et plus encore, ont survécu jusqu'à nos jours, même si la coutume de prendre une femme esquimaude a disparu il y a plus de cent ans. [Traduction des auteurs]

Au Labrador sud, Kennedy (1995, p. 108) mentionne la présence jusqu'aux années 1950 de l'attelage canin, avec recours aux commandes vocales inuit pour diriger les chiens. Il signale aussi l'utilisation de peaux de phoque pour fabriquer des lanières de cuir et des bottes, d'os de baleine pour recouvrir la surface inférieure des patins de traîneau, et du couteau féminin inuit, qu'on appelle $u l u$ ou d'un terme dérivé de ce mot inuktitut.

$\mathrm{Au}$ détroit de Belle Isle enfin, à Blanc-Sablon au milieu des années 1960, Breton (1968) insistait sur le fait que les techniques d'exploitation du milieu naturel - pêche à la morue, au hareng, au loup-marin (à l'aide de filets), au saumon et à la truite ; chasse au caribou ; piégeage ; coupe du bois ; cueillette (des œufs et des baies) ; horticulture - étaient d'origine européenne ${ }^{36}$. On a toutefois emprunté un certain nombre de traits à la culture matérielle inuit : bottes, moufles et parkas ${ }^{37}$ en peau de loup-marin (en usage jusque vers 1950) ; traîneau et attelage de chiens (ces animaux étant remplacés par des motoneiges à partir de 1964).

Dans la zone du détroit, la tradition orale a préservé d'autres éléments liés à la présence inuit. On a mentionné plus haut les réminiscences au sujet de Jenny Menouque et de sa petite-fille, encore vivaces au milieu des années 1960. La mémoire collective conserve aussi plusieurs récits concernant les Inuit pré- et protohistoriques (Charest 1998, pp. 26-27) : il s'agit des histoires de batailles entre ceux-ci et les Innuat (comme à Battle Harbour - près du cap Charles - et à Eskimo Island - dans l'archipel de la rivière Saint-Paul) ${ }^{38}$, mais aussi de descriptions de structures en pierres et de sépultures attribuées aux Inuit et de découverte d'artefacts typiques de leur culture (lampes en stéatite, pointes de harpons, etc.). Un entretien, mené en 1972, avec deux aînés d'Old Fort relate des combats entre Inuit et Amérindiens à Bottle (ou Battle ?) Neck, près du lac Salé, à la rivière Saint-Paul ${ }^{39}$. Ces aînés rapportent également la présence de restes en pierre et d'artefacts inuit aux lieudits Brown Nascapi et Blueberry Hill (rivière Saint-Paul), ainsi qu'à l'extrémité ouest d'Eskimo Island et dans plusieurs autres îles entre Old Fort et Blanc-Sablon ${ }^{40}$.

Au-delà des récits historiques et des vestiges matériels, les Inuit semblent occuper une place de choix dans l'imaginaire des résidents du détroit de Belle Isle. Une curieuse histoire rapportée par Charest (1998, p. 27) raconte que le postillon Joseph (Jos) Hébert (1830-1919), chanté par l'auteur compositeur interprète Gilles Vigneault (lui-même originaire de la Moyenne-Côte-Nord), déterra une nuit le cadavre d'un Inuk nommé Cubbler (Kubluq), enterré dans l'île Verte en 
face de Blanc-Sablon. Il coupa la tête du mort et la mit dans une boîte remplie de sel afin d'aller la vendre à Québec. Mais le mauvais temps et la malchance le poursuivirent sans arrêt, " comme si la tête de l'Esquimau ne voulait pas partir ", selon l'informatrice citée par Charest (1998, p. 27) ${ }^{41}$. Certaines croyances locales pourraient être, elles aussi, liées, mais de façon plus indirecte, à la présence autochtone. Tremblay, Charest et Breton (1969, p. 233) rapportent ainsi l'apparition de chiens fantômes (des huskies ou « chiens esquimaux ») dans l'archipel de Saint-Augustin et dans les îles de Blanc-Sablon ${ }^{42}$. On les entend souvent aboyer, il arrive même qu'on les aperçoive, mais on n'a jamais réussi à les attraper. À Lodge Bay près du cap Charles, plusieurs personnes racontaient encore, durant les années 1980, voir apparaître par temps de grosse neige "Old Smoker» (« le vieux fumeur »), le fantôme - vêtu de blanc et tiré par cinq chiens blancs d'un conducteur de traîneau perdu dans la tempête. Kennedy (1996a), qui rapporte le fait, mentionne qu'un Inuk vivant autrefois dans la région était appelé Smoker et que, pour les Settlers métis, ce fantôme pourrait symboliser l'Autre autochtone de qui ils descendent en partie ${ }^{43}$.

Plus directement, il est possible que des traditions observées au détroit de Belle Isle et, de façon générale, au Labrador méridional, soient d'origine inuit. C'est le cas par exemple d'un récit sur les sirènes recueilli à Saint-Augustin (Tremblay, Charest et Breton 1969, p. 234) : une sirène échouée sur la grève supplie un pêcheur de la remettre à l'eau. Pour ce faire, il faut que celui-ci l'aborde par derrière et la pousse vers la mer, en émettant un vœu qui sera exaucé. Toute autre manière de procéder risque d'entraîner la mort du pêcheur. Commentant l'une de ses sculptures, l'artiste inuit Davidialuk Alasuaq, de Puvirnituq (Québec arctique), raconte qu'elle représente l'histoire d'Iqaluunappaa («la moitié de poisson »). Échouée sur la grève, cette sirène demande au chasseur qui l'a aperçue de la remettre à l'eau. En remerciement, elle lui apportera le lendemain tout ce qu'il souhaite avoir, mais, sous peine de mort, le chasseur ne doit pas la toucher. Il lui faut utiliser un bâton pour la repousser vers la mer. Revenu sur place le lendemain, il y trouve tous les objets qu'il avait demandés (Saladin d'Anglure 1978, p. 80).

La direction d'un emprunt éventuel est discutable (les Inuit ont bien pu adopter un thème légendaire européen, plutôt que l'inverse) ${ }^{44}$, mais les similitudes entre la sirène de Saint-Augustin et l'Iqaluunappaa de Puvirnituq (toutes deux pourvoyeuses de bienfaits, mais dangereuses à manipuler) dénotent quand même l'existence de symboles mythiques communs jouant un rôle significatif dans les deux cultures. Plus représentative peut-être d'une influence inuit directe, une coutume en usage chez les métis du Labrador central à la fin du $\mathrm{XIX}^{\mathrm{e}}$ siècle exigeait qu'en consommant du caribou et du phoque au cours d'un même repas, on boive au moins une gorgée d'eau entre les deux types de viande (Labrèche et Kennedy 2007, p. 56). On reprenait ainsi de manière atténuée un 
tabou commun à plusieurs groupes inuit - sans doute transmis par les ascendantes autochtones des Settlers métis - qui interdisait totalement de consommer des gibiers marins et terrestres pendant un même repas.

\section{LE TRAÎNEAU ET L'ATTELAGE DE CHIENS}

Dans leurs travaux sur la sous-aire culturelle du Labrador méridional, tous les auteurs consultés mentionnent le complexe traîneau/attelage canin comme l'un des principaux éléments de culture matérielle emprunté aux Inuit. Les voyageurs ayant visité le détroit de Belle Isle et la Basse-Côte-Nord durant la seconde moitié $\mathrm{du} \mathrm{XIX}^{\mathrm{e}}$ siècle en présentent généralement des descriptions assez détaillées, comme l'ont fait aussi quelques ethnologues plus contemporains. Ce moyen de transport hivernal reste encore très vivant dans la mémoire des aînés d'aujourd'hui, même si la motoneige a remplacé les chiens au début des années $1960^{45}$. C'est pourquoi nous allons maintenant nous arrêter sur cet exemple marquant d'apport autochtone à la culture métisse de la région.

Le complexe traîneau/attelage a été emprunté aux Inuit du nord du Labrador qui, comme on l'a vu, ont fréquenté la partie méridionale de la région et la Basse-Côte-Nord jusqu'au milieu du XIX ${ }^{\mathrm{e}}$ siècle. Des descriptions de 1770 (détroit de Belle Isle) et 1771 (Nain, au Labrador septentrional) citées par Taylor (1974, pp. 37-38) mentionnent des traîneaux faits de deux patins reliés par des barres transversales, longs de 5 à $6,5 \mathrm{~m}$ et larges de 45 à $75 \mathrm{~cm}$. On y attelle de 2 à 25 chiens, pour une moyenne de 15,6 chiens par attelage ${ }^{46}$. C'est beaucoup plus que ce que l'on retrouve chez les autres groupes inuit - et qu'on retrouvera plus tard dans la région - mais, selon Taylor (ibid.), un tel nombre d'animaux de trait s'accorde à la longueur du traîneau (très supérieure, elle aussi, à ce qui existe ailleurs) et à sa charge (un peu plus de trois quarts de tonne).

Hawkes (1916, pp. 64-68) décrit les traîneaux et les attelages qu'il a observés en 1914 chez les Inuit du Labrador nord. Les plus longs traîneaux (7,2 m) se démarquent encore par leur taille, mais les plus courts $(3 \mathrm{~m})$ se rapprochent beaucoup - tant en longueur qu'en largeur $(60 \mathrm{~cm})$ - de ce qu'on observe ailleurs dans l'Arctique. Comme le fait remarquer Ben-Dor (1966, pp. 33-34), les traîneaux et les traits d'attelage tendent à être plus longs dans les zones de toundra (le quart septentrional de la côte du Labrador), où la présence d'arbres n'entrave pas la course des chiens, que dans les régions boisées du sud.

Selon Hawkes (ibid.), le traîneau inuit du Labrador comprend trois parties : deux patins de bois joints par des barres transversales, elles aussi en bois, et une semelle en os de baleine - fixée par des chevilles de bois et/ou d'os - sous les patins ${ }^{47}$. Ceux-ci sont liés aux barres par des lanières de cuir de phoque. Il n'y a pas de montants verticaux à l'arrière. Le traîneau est tiré par un attelage de 6 à 8 chiens harnachés. Chaque animal y est relié par un trait distinct, de longueur 
différente pour chacun, ce qui permet à l'attelage de former une seule ligne au besoin, sans risquer de se nuire. Chaque trait est rattaché à une lanière en forme de V à l'avant du traîneau. Harnais et traits d'attelage sont en cuir de phoque.

Ce type de traîneau et d'attelage correspond en tous points au modèle courant jusqu'aux années $1960 \mathrm{chez}$ les Inuit de l'Arctique oriental canadien ${ }^{48}$. À quelques détails près, il a été adopté tel quel par les individus d'origine métisse ou européenne occupant la sous-aire culturelle du Labrador méridional (Figure 2).

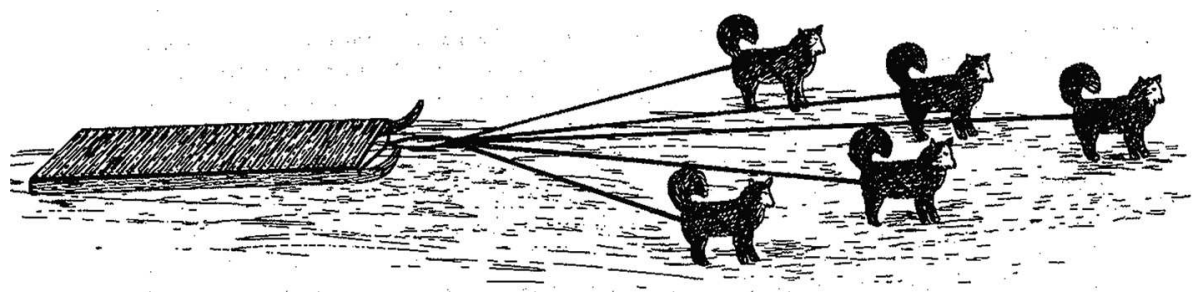

FIG. 2 - Traîneau et attelage (Source : Breton 1968, p. 105).

\section{LE TRAÎNEAU}

D'après ce qui a été observé au détroit de Belle Isle et sur la Basse-Côte-Nord pendant environ un siècle (de 1858 au début des années 1960$)^{49}$, le traîneau est très semblable dans sa forme et dans les matériaux qui le composent aux véhicules les plus courts décrits par Hawkes (1916) : deux patins à pointes avant, effilées en courbe ${ }^{50}$, reliés par des barres transversales, le tout en bois, d'une longueur de 2,7 à $3,6 \mathrm{~m}$ et d'une largeur de 60 à $75 \mathrm{~cm}$. Stearns (1884, p. 145), qui a visité la zone de Blanc-Sablon/rivière Saint-Paul au début des années 1880, affirme toutefois que des traîneaux pouvaient atteindre $3,9 \mathrm{~m}$ de long et $90 \mathrm{~cm}$ de large.

Selon les descriptions les plus anciennes, patins et barres étaient liés ensemble par des lanières de cuir de phoque, comme c'était encore le cas au Labrador septentrional en 1914 (Hawkes 1916), et chez les Inuit du nord du Québec arctique en 1966 (Dorais 1997). À partir de la fin du XIX ${ }^{\mathrm{e}}$ siècle cependant, le « fil à saumon » (corde servant à fabriquer les filets de pêche), passé dans des trous percés au fer rouge, semble avoir définitivement remplacé le cuir au Labrador méridional. Qu'il soit en lanières de peau de phoque ou en corde, ce genre d'attache a l'avantage de conférer de l'élasticité au traîneau, puisqu'il donne du jeu aux patins quand ils frappent un trou ou une bosse, ce qui évite les bris. À une époque plus récente (quand les motoneiges ont pris la place des chiens), on a toutefois remplacé l'attache élastique par des clous, comme l'a observé Kennedy (1996a, p. 49) au cap Charles au début des années 1980, et comme l'ont mentionné les personnes rencontrées par Céré à Blanc-Sablon et à Old Fort en 2011. 
Pour ralentir l'usure des patins, on recouvrait leur partie inférieure, en contact avec le sol, de morceaux d'os de baleine d'environ 1,25 cm d'épaisseur, fixés par des chevilles de bois et/ou d'os. À partir du Xx $\mathrm{x}^{\mathrm{e}}$ siècle (Hawkes le signalait déjà au Labrador septentrional en 1914), le métal remplaça l'os. Un informateur d'Old Fort mentionne que, pour faciliter la glisse, la semelle d'os ou de métal était souvent recouverte d'une mince couche d'eau qui glaçait immédiatement. Il s'agit là d'une technique inuit, en usage au Québec arctique jusqu'aux années $1960{ }^{51}$.

Tant au Labrador que sur la Basse - et même la Moyenne - Côte-Nord, le traîneau est désigné, selon les sources, par une variante du terme inuktitut qamutiik, komatik, komotic ou commetique en anglais, cométique en français. Ce nom est encore utilisé même si, avec le temps, le véhicule métis s'est légèrement modifié par rapport à son modèle autochtone. Par exemple, il n'y a pas d'espaces vides entre les barres reliant les patins du traîneau, celles-ci formant donc une sorte de plancher. Sur les traîneaux inuit en revanche, et ce encore de nos jours, on laisse souvent un intervalle d'environ 10-12 cm entre chaque barre transversale. Dès les années 1860, les auteurs mentionnent que les propriétaires de traîneaux de voyage garnissent leurs véhicules de peaux de phoque ou d'ours clouées aux barres et cousues ensemble, pour que les passagers soient mieux protégés $\mathrm{du}$ froid ${ }^{52}$. On peut aussi y fixer un siège ou une boîte de bois ${ }^{53}$. Si les traîneaux inuit ont bien un contenant pour la cargaison, on ne les garnit jamais de fourrures.

\section{L'ATTELAGE DE CHIENS}

Le traîneau est tiré par un attelage de 5 à 9 chiens ( 5 ou 6 le plus souvent), mais il peut arriver que, pour une raison quelconque (manque de moyens, légèreté de la charge), on n'y attelle que deux ou trois animaux (Stearns 1884, p. 147). Originellement de race esquimau (husky), les chiens se sont peu à peu mélangés avec d'autres races introduites dans la région, mais les caractères physiques et comportementaux d'origine sont encore apparents chez la plupart d'entre eux.

Chaque animal est attelé au traîneau par un trait individuel dont la longueur varie d'un chien à l'autre, ce qui permet à l'attelage, on l'a mentionné plus haut, de tirer en ligne ou de se déployer en éventail. C'est le chien de tête (lead dog) ${ }^{54}$ - souvent une femelle - qui guide les autres, en sachant lui-même où aller ou en obéissant promptement aux ordres de son maître. Chacun des traits est rattaché par une boucle à une amarre (la bride) en forme de $\mathrm{V}$ à l'avant du traîneau, le pithook (Huard 1897, p. 280), de l'inuktitut pituk qui désigne cette même partie de l'attelage inuit. Le trait du chien de tête peut être long de 9 à $18 \mathrm{~m}$, chaque animal étant en retrait d'un à deux mètres par rapport à celui qui le précède.

Le cuir de phoque a progressivement été remplacé par la corde à filet ou le fil de ligne à pêche (bank line) pour la fabrication des traits. Un aîné métis du 
Labrador central, Dennis Blake (1976), se rappelle que le cuir était plus durable que la corde (il s'usait sans jamais briser), mais qu'il avait tendance à s'étirer à l'humidité. Quel que soit le matériau en usage, l'extrémité du trait est rattachée au harnais du chien par une boucle en corde ou, plus récemment, par une agrafe en métal. Il ne faut pas faire de nœud, pour ne pas irriter le dos de l'animal (ibid.).

En cuir de phoque à l'origine, le harnais canin a lui aussi fini par être fabriqué avec de la corde. On préférait même cette dernière, le cuir n'étant utilisé, à l'époque de Dennis Blake (années 1950) que quand on manquait de corde (ibid.) ${ }^{55}$. Un informateur d'Old Fort se souvient qu'une peau de phoque du Groenland d'environ $1,5 \mathrm{~m}$ de long, préalablement grattée et séchée, puis découpée en lanières de $7,5 \mathrm{~cm}$ de large, suffit à la fabrication d'un harnais à chien. Celui-ci forme des boucles où on passe la tête et les pattes avant de l'animal, qui tire donc du poitrail et des épaules. Il s'agit là du modèle inuit ${ }^{56}$ que les métis décorent parfois de pièces de drap ou de laine colorée.

Au printemps, quand la neige et la glace fondent le jour pour regeler pendant la nuit, elles forment des aiguilles qui peuvent blesser les pattes des chiens. On chausse alors ceux-ci de petites bottes en peau de phoque ou, parfois, en laine.

\section{COMMANDER L'ATTELAGE}

À l'instar de ses collègues inuit, le conducteur d'attelage peut faire usage d'un fouet en cuir, parfois très long jusqu'à 21,5 m selon Ferland (1877, p. 115). Il l'utilise pour frapper les chiens qui désobéissent, en criant d'abord le nom du délinquant. Règle générale, on juge nécessaire de battre un animal qui se comporte mal (qui ronge son harnais ou son trait ou qui attaque les chiens d'un autre attelage, par exemple), mais la violence gratuite est considérée comme condamnable.

En fait, c'est par la voix que le conducteur contrôle ses chiens. Les commandements canins, transcrits dans les textes ou rapportés par les informateurs, découlent du modèle inuit en usage jusqu'à récemment au Labrador septentrional et au Québec arctique. On trouvera à la Figure 3 une comparaison entre ces onomatopées.

\begin{tabular}{|l|l|l|l|l|l|l|}
\hline \multicolumn{1}{|c|}{ Ordres } & \multicolumn{1}{|c|}{$\begin{array}{c}\text { Stearns } \\
(1884)\end{array}$} & $\begin{array}{c}\text { Huard } \\
(1897)\end{array}$ & $\begin{array}{c}\text { Kennedy } \\
(1996 \mathrm{a})\end{array}$ & $\begin{array}{c}\text { Entretiens } \\
\text { recueillis par } \\
\text { Céré (2011) }\end{array}$ & $\begin{array}{c}\text { Hawkes } \\
\text { (1916) }\end{array}$ & $\begin{array}{c}\text { Schneider } \\
(1970)\end{array}$ \\
\hline Partez! & & pouitt pouitt & & sifflement & houitt houitt & ouitt ouitt \\
\hline Arrêtez! & & haa haa & woh(w) woh(w) & woh(w) woh(w) & aa aa & aaa aaa \\
\hline À droite! & owk owk & hoc hoc & ouk ouk & awk awk & awk awk & awk awk \\
\hline À gauche! & rudder, da da & rre rre & outta outta & retta, retter & rrr rrr & rra rra \\
\hline
\end{tabular}

FIG. 3 - Les commandes pour diriger l'attelage. 
Il y a quatre commandements de base : «Partez! », «Arrêtez! », « Virez à droite ! », «Virez à gauche ! ». Selon Huard (1897, p. 281), l'ordre de partir se dit pouitt $^{57}$, une interjection qu'on répète à plusieurs reprises, comme toutes les autres d'ailleurs. Ce mot correspond d'assez près à l'inuktitut du Labrador (houitt ; voir Hawkes 1916, p. 68) et à celui du nord du Québec arctique (ouitt; voir Schneider 1970, p. 79) ${ }^{58}$. Selon la personne interviewée à Old Fort en 2011, pour faire démarrer l'attelage, on émet un simple sifflement ou bien on claque des mains. Un film documentaire tourné à La Tabatière à la toute fin des années 1950 montre un conducteur de traîneau qui siffle des tss tss répétés pour faire avancer ses chiens ${ }^{59}$. Ce sifflement pourrait peut-être tirer son origine du $(h)$ ouittlpouitt inuit, une syllabe sifflante elle aussi, mais articulée au niveau des lèvres plutôt qu'au niveau de la langue.

Pour Huard (1897), le signal d'arrêt consiste en l'émission d'un long ( $h) a a$, comme en inuktitut. Au Labrador méridional cependant, à une période plus récente tout au moins (milieu du $\mathrm{xx}^{\mathrm{e}}$ siècle), ce commandement a été remplacé par l'interjection woh $(w)$, en usage dans le monde anglophone pour faire stopper les chevaux. En revanche, l'ordre de tourner à droite montre partout une remarquable similitude. Selon tous les auteurs et informateurs, c'est par un awk ou un son s'en approchant ( $h o c, o w k$, ouk) qu'on ordonne aux chiens de virer à dextre, comme c'est le cas en inuktitut du Labrador et du Québec arctique.

En inuktitut, l'ordre de tourner à gauche est intimé en émettant à plusieurs reprises un $\mathrm{r}$ apical ("r roulé ») : rrr rrr au Labrador septentrional, rra rra au Québec arctique. Au Labrador sud comme au détroit de Belle Isle et sur la Basse-Côte-Nord, on a généralement conservé ce phone apical (rre rre selon Huard), mais en le faisant souvent suivre d'une syllabe débutant par une occlusive dentale (d ou t). Autant chez Stearns (1884, p. 150) que chez un informateur de 2011 (Old Fort), cela donne des formes comme rudder, retta ou retter. Dans certaines versions, le $\mathrm{r}$ apical initial disparaît et l'exclamation « à gauche » se réduit, sur le plan consonantique, à l'occlusive dentale : $d a d a^{60}$, comme alternative à rudder selon Stearns (ibid.) et outta selon Kennedy (1996a).

Enfin, Stearns est le seul à mentionner l'exclamation $h i$ hi, pour inciter les chiens à démarrer en vitesse. Celle-ci se rapproche du iiii, entendu dans le nord du Québec arctique et destiné à encourager la course de l'attelage (Dorais 1997, p. 266).

Toutes ces commandes orales permettent de diriger très précisément le mouvement des chiens. Les aînés interviewés à Old Fort en donnent un exemple amusant :

L'oncle Sam Fequet jeta son chapeau à terre en sortant du magasin de la Compagnie de la Baie d'Hudson. Il cria « Retta » [ À gauche!»] et ses chiens virèrent de bord et revinrent à l'endroit exact où le chapeau était tombé. [Traduction des auteurs] 


\section{L'UTILISATION DE L'ATTELAGE}

Dans un pays sans routes, l'attelage de chiens a constitué jusqu'aux années 1960 le seul moyen de transport hivernal, durant la saison où les voies maritimes sont impraticables en raison des glaces. Depuis 2010, un chemin gravillonné (avec des sections asphaltées) relie le Labrador central au détroit de Belle Isle - de Happy Valley (ville elle-même raccordée au réseau routier québécois) à Old Fort -, mais sur la Basse-Côte-Nord, c'est encore le traîneau, tiré par une motoneige, qui permet de se déplacer d'un village à l'autre pendant l'hiver, reliant ainsi la zone de Belle Isle au reste du Québec par voie terrestre.

Dans de bonnes conditions (neige dure, basse température, beau temps), les attelages d'autrefois pouvaient parcourir de 90 à $140 \mathrm{~km}$ par jour. Outre le transport entre communautés (même la poste utilisait le traîneau et les chiens), on avait recours à l'attelage pour rapporter du bois de chauffage des forêts, situées à quelque distance de la côte ${ }^{61}$, ou pour déplacer des charges à l'intérieur et aux environs des villages.

Les chiens étaient appréciés pour leur utilité et chacun avait son nom ${ }^{62}$, mais on ne les gâtait pas. Ils ne pénétraient jamais dans les maisons, même pas les chiots (Junek 1937, p. 37) ${ }^{63}$. En hiver, on les nourrissait une fois par jour, généralement le soir, de poisson ou de déchets de loup-marin. Plus récemment, on leur a donné du porridge acheté au magasin. En été, par contre, ils étaient laissés à eux-mêmes et se sustentaient de poissons morts, de débris d'animaux marins ou, même, de matières fécales. Dans certaines régions, on les emmenait pour l'été dans des îles côtières, où on allait les rechercher à l'automne. Il s'agit là de pratiques très proches de celles des Inuit.

Selon les aînés interviewés à Old Fort, le soin et la conduite des attelages étaient affaire uniquement masculine et ne concernaient pas du tout les femmes. Les infirmières et les enseignantes faisaient cependant exception, car leur employeur mettait un attelage à leur disposition. Elles recevaient toutefois beaucoup de conseils de la part des hommes du village.

L'un des aînés susmentionnés a été chargé d'éliminer les chiens à partir de 1964, année où les premières motoneiges ont fait leur apparition dans la région. La plupart des propriétaires d'attelages déploraient cette élimination, mais ils n'avaient guère le choix, puisque l'argent jusque-là consacré à l'achat de porridge pour nourrir les animaux devait maintenant servir à se procurer de l'essence pour la motoneige. L'aîné en question emmenait les chiens à Greenland Pond, à proximité du village d'Old Fort, où il les abattait au fusil. Quelques-uns seulement furent gardés en vie pour servir d'animaux de compagnie. Des scènes semblables se déroulèrent ailleurs au Labrador méridional - comme aussi en pays inuit - à la même époque et pour les mêmes raisons. 


\section{CONCLUSION}

Dans les pages qui précèdent, nous avons vu comment, à partir $\mathrm{du} \mathrm{XIX}^{\mathrm{e}}$ siècle, une culture métisse s'est développée au détroit de Belle Isle, au Labrador sud et sur la Basse-Côte-Nord du golfe du Saint-Laurent. Issue des contacts entre anglophones d'origine britannique, Inuit et, dans une moindre mesure, Amérindiens innuat et Québécois francophones, cette culture originale a permis aux divers groupes humains implantés dans la région - une zone que Charest (2007) qualifie de sous-aire culturelle du Labrador méridional - d'exploiter de façon optimale toutes les ressources de leur milieu, grâce en partie aux emprunts à la technologie inuit, dont le complexe de l'attelage de chiens constitue un exemple probant.

Cette culture métisse, dans ses dimensions matérielles tout au moins, s'est progressivement effacée à partir du deuxième tiers $\mathrm{du} \mathrm{xx}^{\mathrm{e}}$ siècle, sous les effets conjugués de la mécanisation, de l'ouverture sur le monde et de la modernisation des conditions d'existence qui s'en est suivie. Des apports autochtones au Labrador méridional, il ne subsiste plus guère aujourd'hui - outre des récits et des souvenirs - que le traîneau de type inuit ${ }^{64}$, maintenant tiré par une motoneige plutôt que par des chiens.

Mais cela n'épuise pas la question. On a vu que, parallèlement au métissage culturel, il y a également eu des croisements biologiques entre les pêcheurs anglo-saxons et les quelques familles inuit venues s'installer dans la région au début du XIX ${ }^{\mathrm{e}}$ siècle. De nos jours, environ $60 \%$ des quelque 10000 habitants du Labrador sud, du détroit de Belle Isle et de la Basse-Côte-Nord compteraient au moins un ascendant inuit dans leur généalogie ${ }^{65}$.

Tout cela n'aurait qu'un intérêt anecdotique si l'évolution des politiques canadiennes à l'égard des autochtones et l'émergence chez ceux-ci d'une affirmation identitaire très forte n'avaient pas donné un sens nouveau à l'ascendance métisse inuit au Labrador méridional. S'ils peuvent démontrer qu'ils possèdent leurs « propres coutumes, façons de vivre et identité collective reconnaissables et distinctes de celles de leurs ancêtres indiens ou inuit d'une part et de leurs ancêtres européens d'autre part », selon les termes du jugement Powley de 2003, les habitants métis de la région pourraient se voir reconnaître des droits spécifiques à titre de communautés autochtones. Les pages qui précèdent nous semblent avoir clairement démontré que les «coutumes, façons de vivre et identité collective » au détroit de Belle Isle et dans les zones voisines comportent une forte dimension d'origine inuit, intimement mêlée aux apports européens et amérindiens.

La reconnaissance de cette dimension et, partant, la possibilité de revendiquer des droits territoriaux (de pêche, de chasse, de piégeage et d'exploitation forestière) et administratifs spécifiques pourraient redonner aux résidents du 
Labrador méridional (NunatuKavut et Basse-Côte-Nord) une autonomie locale et régionale - la possibilité de décider eux-mêmes de ce qui est bon pour eux ${ }^{66}$-, mise en péril par la volonté centralisatrice des gouvernements du Canada, de Terre-Neuve et du Québec. L'existence d'une culture métisse propre à la région et historiquement partagée par tous, quelle que soit leur ascendance généalogique particulière, peut constituer un argument important dans la revendication de tels droits (Charest 2007, p. 71). Puisqu'ils constituent des témoins irréfutables de l'origine partiellement indigène de la culture locale, on peut donc considérer l'attelage de chiens et les autres traits culturels d'origine inuit décrits dans cet article comme des symboles forts de l'autochtonie métisse au détroit de Belle Isle et dans les zones adjacentes. *

* Manuscrit reçu en septembre 2011, accepté pour publication en mai 2012.

\section{Notes}

Remerciements : nous remercions sincèrement nos informateurs et informatrices de Blanc-Sablon et Old Fort, tout particulièrement monsieur Dwight Bilodeau, pour leur apport documentaire. Le professeur Paul Charest a commenté de façon très constructive une première version de ce texte et monsieur Galo Luna Penna a eu l'amabilité de traduire notre résumé en espagnol.

1. Par respect pour les langues autochtones, nous avons choisi dans cet article de ne pas soumettre les mots qui en proviennent aux règles du français. Ils n'auront donc pas de marque du féminin ; pour le pluriel, ce sont leurs règles propres (nom singulier : Inuk, Innu ; nom pluriel/adjectif : Inuit/inuit, Innuat/innuat) qui seront appliquées.

2. Comme on le mentionnera en cours d'article, la « sous-culture » du Labrador méridional a aussi emprunté certains traits à la culture innu. Nous limiterons cependant nos propos aux apports inuit puisque, d'une part, les métis de la région se réclament avant tout d'une ascendance inuit et que, d'autre part, la recherche sur les influences amérindiennes au Labrador reste encore largement à faire.

3. Zone s'étendant, pour les besoins de l'article, de Saint-Augustin au cap Charles (Figure 1).

4. Dans la continuité des travaux de Charest $(2007,2008)$, l'aire que nous qualifions de « Labrador méridional » comprend le sud du Labrador (Labrador sud), la zone du détroit de Belle Isle et la Basse-Côte-Nord du golfe du Saint-Laurent.

5. Nom donné régionalement au phoque commun (Phoca hispida) et au phoque du Groenland (Phoca groenlandica).

6. Allusion aux habitations d'hiver semi-souterraines des Inuit, recouvertes d'os (de côtes de baleine en particulier), de pierres et de branchages (lorsqu'ils en ont).

7. Dès la fin du XVII ${ }^{e}$ siècle, les Inuit du Labrador possédaient des barques d'origine européenne, plus solides et maniables que le bateau collectif traditionnel en peau de phoque (umiaq).

8. Entre 1640 et 1690 , ces Inuit du détroit de Belle Isle fréquentèrent de façon saisonnière la Basse-Côte-Nord du golfe du Saint-Laurent, peut-être jusqu'à la Pointe-aux-Esquimaux (aujourd'hui Havre-Saint-Pierre), à environ $450 \mathrm{~km}$ au sud-ouest de Blanc-Sablon (Martijn 1980).

9. Par exemple les mots camara (du français « camarade»), memek (« boire»; de l'inuktitut imiq, « eau »), makagua (« paix »; du basque) et monkoumek (« couteau»; de l'innu muhkuman) (Dorais 1980).

10. La première mission morave fut fondée à Nain en 1771. Selon un recensement de 1773 (Charest 2007, p. 64), Hamilton Inlet (à une centaine de kilomètres au nord de la baie de Sandwich) constituait alors la limite sud du peuplement inuit. 
11. Les Français avaient introduit l'usage du filet maillant pour la capture des phoques. C'est pourquoi on parle de " pêche » au loup-marin en automne (usage du filet) et de « chasse » en hiver sur la banquise (usage du harpon, puis du gourdin).

12. Selon Breton (1968, p. 41), dès la fin du XVIII ${ }^{\mathrm{e}}$ siècle, des Inuit se sont mêlés aux Européens (des employés de compagnies de pêche, en principe) présents dans les archipels de la rivière Saint-Paul et de Saint-Augustin.

13. Appréciées encore aujourd'hui pour leurs qualités isolantes, leur imperméabilité et leur durabilité, mais devenues inutiles en milieu villageois et urbain où le sel de calcium qu'on répand l'hiver dans les rues en ronge rapidement le cuir.

14. En 1825, on fixa à deux kilomètres à l'est de Blanc-Sablon la frontière entre le Bas-Canada (province de Québec) et le Labrador (rattaché à Terre-Neuve, une colonie britannique qui ne se joignit au Canada qu'en 1949). Durant le XIX ${ }^{\mathrm{e}}$ siècle et les premières années du XX⿳⺈, on appelait la Basse-CôteNord « Labrador canadien », en raison de ses ressemblances avec le « Labrador terre-neuvien ».

15. Des francophones s'installèrent ailleurs aussi, mais ils s'y assimilèrent aux anglophones par intermariage, ne préservant de leur identité d'origine que leur religion (catholique) et certains noms de famille (c'est le cas, entre autres, à Saint-Augustin ; voir Tremblay, Charest et Breton 1969).

16. Il pourrait s'agir du nom inuit Palluq.

17. Selon le site de la Labrador Metis Nation (www.labradormetis.ca), consulté le 28 mars 2011.

18. Les entrevues sur les apports culturels inuit et sur l'attelage de chiens, menées en 2011 par Céré (2012), avaient pour objectif explicite de recueillir de la documentation pour le présent article ; l'auteur a alors séjourné au détroit de Belle Isle pour préparer un mémoire de maîtrise portant sur un tout autre thème, celui des construits sociaux du désastre et de la sécurité civile.

19. Prise dans son acception géopolitique, il s'agit de la partie québécoise de l'aire étudiée ici ; elle s'étend de Blanc-Sablon à Kegaska.

20. Labrador sud ou Labrador nord, cette seconde région demeurant majoritairement peuplée d'Inuit (près de 1000 en 1855 ; plus de 2000 de nos jours).

21. On éprouvait, semble-t-il aussi, une certaine gêne à parler de ces choses, les sentiments de mépris à l'égard des autochtones étant encore assez vivaces.

22. Tant numériquement que proportionnellement, ceux-ci étaient nettement plus nombreux du côté terre-neuvien de la frontière (4 500 personnes) que du côté québécois (1 500 individus).

23. Ces huit traits sont les suivants (Charest 2008, p. 24) : 1) l'adaptation au milieu et l'exploitation de ressources naturelles variées ; 2) l'héritage culturel autochtone ; 3) le pluralisme occupationnel et le cycle annuel des activités de production ; 4) le dualisme résidentiel, la transhumance et la dispersion du peuplement ; 5) l'économie et la technologie centrées sur la pêche, la chasse et le piégeage ; 6) la famille et le poste de pêche comme unités socio-territoriales de base ; 7) le faible développement politique ; 8) la multi-confessionnalité religieuse.

24. Par exemple, il n'y a pas eu de métissage inuit sur la Moyenne-Côte-Nord, et celle-ci est majoritairement peuplée de francophones originaires d'Acadie ou de la vallée du Saint-Laurent, mais ses habitants ont adopté l'usage du traîneau à chiens (Dubreuil 1997) et des bottes en peau de phoque d'origine inuit. Au Labrador septentrional, en revanche, où les résidents métis partagent le territoire avec des Inuit et des Innuat, les traits biologiques et culturels inuit sont plus marqués qu'au sud, et la population a dû s'adapter à un environnement naturel de type semi-arctique (Charest 2007, p. 70).

25. En 1977, Dorais croisa à Happy Valley (Labrador central) une dame âgée d'apparence typiquement inuit. S'étant adressé à elle en inuktitut, il l'entendit répondre : " I'm not a Husky ; I don't speak that language » ("Je ne suis pas une Husky [terme péjoratif désignant les Inuit]; je ne parle pas cette langue »). La dame en question était une métisse originaire de la baie de Sandwich.

26. Ce titre fut enchâssé dans la Constitution canadienne de 1982, qui reconnaît - sans toutefois les définir - l'existence de droits spécifiques aux personnes et aux collectivités d'origine amérindienne, inuit ou métisse.

27. Au-delà de la simple gestion territoriale, la reconnaissance légale de droits indigènes rend légitime et politiquement efficace une forme d'identité - définie comme « autochtone » - née à l'époque 
coloniale et à laquelle les premiers occupants du territoire n'ont jamais renoncé, malgré les tentatives d'assimilation du pouvoir européen (Friedman 2009).

28. Selon les termes de l'entente, les Qallunaangajuit ou Settlers, originaires du Nunatsiavut, sont reconnus comme des Inuit de plein droit, au même titre que les autochtones ayant toujours été considérés comme tels. L'entente s'applique également aux anciens résidents du Nunatsiavut ayant migré au Labrador central.

29. Les métis du Labrador sud n'ont jamais parlé inuktitut - ce sont plutôt les Inuit immigrés dans la région qui apprenaient l'anglais - mais, selon Kennedy (1996b), certains se sont mis à l'apprentissage de cette langue pour mieux marquer leur identité autochtone.

30. Nicholas Shattler, communication personnelle, $1^{\mathrm{er}}$ septembre 2011.

31. Il est intéressant de noter que les emprunts aux Inuit relèvent tous de l'adaptation à un milieu côtier. Pour leurs activités en milieu forestier, les pionniers ont adopté des éléments de culture innuat : canoës, raquettes à neige, mocassins.

32. Ils correspondent d'assez près par exemple (attelage canin, parka, bottes) aux "modèles empruntés des Esquimaux » observés par Junek (1937, p. 103) à Blanc-Sablon en 1934.

33. Appelés Qallunaangajuit («partiellement européens ») par les Inuit locaux.

34. Selon des commentaires entendus au détroit de Belle Isle par Céré (2012), on ne pourrait pas construire de maisons de neige dans cette région, le climat y étant plus tempéré qu'au nord et la neige mal adaptée à la construction d'iglous.

35. Les métis du Labrador central avaient peut-être délaissé l'usage du grattoir (kiliutak), ou n'avaient jamais emprunté cet outil.

36. On consulte cependant parfois les Innuat de Pakuashipi (Saint-Augustin) pour localiser les hardes de caribous.

37. Appelées cossack («casaque»), et non pas dickie ou dickey (atigik) comme au Labrador central et septentrional.

38. Selon la tradition, ces batailles - également mentionnées par Breton (1968, p. 41) - auraient forcé les Inuit à quitter la région et à migrer vers le nord. Notons que la rivière Saint-Paul était autrefois appelée rivière aux Esquimaux (Charest 1998, p. 26).

39. Entretien gracieusement mis à la disposition des auteurs en 2011, par un informateur d'Old Fort.

40. L'habitat inuit dans la région est décrit comme étant surtout insulaire (archipels de SaintAugustin et de la rivière Saint-Paul, îles du large de Blanc-Sablon et des environs du cap Charles), alors que celui des Innuat est plutôt à l'intérieur des terres. Les deux aînés d'Old Fort mentionnent expressément « qu'ils n'ont jamais vu d'Indiens sur ces îles».

41. Charest reprend des données de terrain inédites recueillies par l'anthropologue Pierre Beaucage à La Tabatière en 1967.

42. Entre 2004 et 2010, Céré (2012) a entendu de telles histoires et réminiscences de la bouche d'aînés hospitalisés à Blanc-Sablon.

43. Notons que, dans le nord du Labrador, les Inuit et les Settlers attribuent à « Old Smoker »-qui apparaît là-bas aussi - une origine terre-neuvienne (Ryan 1990, pp. 55-56). Cela en fait quand même une figure de l'Autre, d'un Autre non autochtone, étranger à la population locale, mais dont certains (les métis) tirent une ascendance partielle.

44. Notons toutefois qu'Iqaluunappaa et la sirène du détroit de Belle Isle sont apparentées aux mermen que les Inuit du nord de l'Alaska prennent parfois dans leurs filets. Alliant un corps de phoque à une tête humaine, le merman doit être relâché, sous peine de mort, par le chasseur qui l'a attrapé. $\mathrm{Si}$, ce faisant, ce dernier prononce le nom d'un animal qu'il aimerait prendre, le merman le lui enverra en guise de remerciement (Spencer 1959, pp. 261-262).

45. Mais le traîneau, maintenant attelé à la motoneige, a survécu sous une forme assez semblable à ce qu'il était autrefois.

46. Selon les calculs de Taylor faits à partir de l'ensemble des mentions d'attelages retrouvées dans les documents d'époque. 
47. À l'époque où Hawkes (1916) a effectué ses observations, en 1914, on commençait déjà à remplacer l'os de baleine par du métal. À Makkovik, en 1962-1963, les traîneaux (kamotik) settlers et inuit observés par Ben-Dor (1966), similaires à ceux décrits par Hawkes, étaient uniformément chaussés de métal.

48. Pour des descriptions détaillées du traîneau et de l'attelage chez les Inuit de l'Arctique oriental canadien, voir, entre autres, Boas (1964 [1888], pp. 121-130) et Turner (1979 [1894], pp. 95-99).

49. Par des voyageurs, comme Ferland (1877 [1859], pp. 112-115), Hind (1863, pp. 157-158), Stearns (1884, pp. 145-151), Gregory (1886, pp. 44-46) ou Huard (1897, pp. 277-283), ainsi que par des ethnologues tels que Junek (1937, pp. 37-38), Breton (1968, pp. 101-106) ou Kennedy (1996a, p. 49). Charest (2005, p. 124) signale des mentions de traîneaux et d'attelages antérieures à cette période, faites par Audubon (1960) en 1833, Bayfield (1860) en 1834 et Bowen (1856) en 1855.

50. Ces pointes sont appelées « chaperons » en français local (Huard 1897, p. 279).

51. Sous la glaçure, les Inuit enduisaient aussi les patins d'une couche de boue congelée.

52. De nos jours, on utilise des couvertures feutrées. Les traîneaux modernes doivent être assez gros pour qu'on puisse y charger une motoneige en panne afin de la ramener au village.

53. Appelée coachbox ou stumpbox au cap Charles (Kennedy 1996a, p. 49).

54. Appelé « chien de l'avant » sur la Basse-Côte-Nord, selon Ferland (in Charest 2008, p. 23). Il s'agit peut-être là d'une traduction littérale de l'inuktitut sivulirti (« qui marche en avant des autres »), nom donné au chien de tête par les Inuit.

55. Le harnais de corde était doublé à l'intérieur de toile de coton (cotton duck) ou de molleton (duffle), pour le rendre plus confortable au chien.

56. Comme au Labrador méridional, les Inuit ont, eux aussi, remplacé le cuir par de la corde ou des bandes de coton.

57. Nous adoptons une graphie représentant le mieux possible la prononciation française, mais qui ne correspond pas toujours à celle des différents auteurs.

58. Schneider (1970) a colligé ses données lexicales au début des années 1950.

59. Il s'agit du court métrage L'Anse Tabatière, réalisé par René Bonnière et Pierre Perrault (1960, Crawley Films, Ottawa).

60. Dans le film tourné à La Tabatière, le conducteur de traîneau dit da da, précédé du nom de l'animal, pour appeler chacun de ses chiens.

61. En forêt et là où la neige était molle, le conducteur et les passagers devaient marcher en raquettes à côté du traîneau plutôt que de monter dessus.

62. À une époque récente tout au moins, il s'agit de noms anglais comme Whistler, Towser, Smokey ou Buster.

63. Dans l'entrevue avec les aînés d'Old Fort, il est toutefois mentionné que le chien de tête était parfois admis dans la maison, quoique cela fût extrêmement rare.

64. Et aussi l'usage de la raquette à neige, empruntée aux Innuat.

65. Chiffres extrapolés à partir des données de Charest (1998) et du site www.labradormetis.ca, consulté le 28/03/2011.

66. Dans son mémoire de maîtrise, Céré (2012) illustre ce désir d'autonomie tel qu'il est manifesté dans un domaine spécifique, celui de la sécurité civile. Les citoyens de Blanc-Sablon souhaitent que le gouvernement québécois tienne compte de leur spécificité régionale. Celle-ci se caractérise par une culture métissée et des savoirs locaux souvent différents de la norme officielle, mais leur permettant d'agir plus adéquatement en matière de mesures d'urgence et de réactions aux désastres. Plus généralement, la population aimerait que le gouvernement reconnaisse ses aptitudes à se gérer elle-même. 


\section{RÉFÉRENCES CITÉES}

Audubon Maria R.

1960 Audubon and his journals, Dover Publications, New York.

BAYFIELD Henry Wolsey

1860 The St. Lawrence pilot. Comprising sailing directions for the gulf and river, Hydrographic Office, Londres.

BEN-Dor Shmuel

1966 Makkovik: Eskimos and settlers in a Labrador community, Institute of Social and Economic Research, coll. "Newfoundland Social and Economic Studies » 4, Memorial University of Newfoundland, St. John's.

BlaKe Dennis

1976 «Labrador crafts. Dog's harness \& trace », Them Days, 2 (1), pp. 27-28.

BoAs Franz

1964 The central Eskimo, University of Nebraska Press, Lincoln [1888].

BORLASE Tim

1994 The Labrador settlers, métis and Kablunângajuit, Labrador East integrated School Board, Happy Valley, Goose Bay.

Bowen Noel H.

1856 "Social conditions of the coast of Labrador », Transactions of the Literary and Historical Society of Quebec, 4, pp. 329-341.

BRETON Yvan

1968 La culture matérielle des Blancs-Sablonnais, Centre d'études nordiques, coll. « Travaux divers »19, Université Laval, Québec.

CÉRÉ Valérie

2012 Les construits sociaux du désastre en région isolée : le cas de Blanc-Sablon, mémoire de maîtrise en anthropologie, Université Laval, Québec [http://www.theses.ulaval.ca/2012/29054.pdf].

Charest Paul

1976 «Stratégies d'adaptation généralisées et écosystèmes spécialisés : le cas de la Côte-Nord du golfe Saint-Laurent », Cahiers d'anthropologie de l'Université Laval, 1, pp. 19-49.

1998 «Les Inuit du Labrador canadien au milieu du siècle dernier et leurs descendants de la Basse-Côte-Nord », Études/Inuit/Studies, 22 (1), pp. 5-35.

2005 La communauté métisse inuit de Saint-Augustin (Basse-Côte-Nord), rapport d'expertise préparé pour l'Alliance autochtone du Québec, Gatineau.

2007 «Le métissage euro-inuit dans la sous-aire culturelle du Labrador méridional », Recherches amérindiennes au Québec, 37 (2-3), pp. 61-75.

2008 «La présence d'Inuits sur la Basse-Côte-Nord au XIX siècle », Littoral, 3, pp. 15-26. 
Clermont Norman

1980 «Les Inuit du Labrador méridional avant Cartwright», Études/ Inuit/Studies, 4 (1-2), pp. 147-166.

DoraIs Louis-Jacques

1980 La langue inuit au sud du Labrador de 1694 à 1785, Musée national de 1'Homme coll. « Mercure », Ottawa.

1997 Quaqtaq. Modernity and identity in an Inuit community, University of Toronto Press, Toronto.

DuBREuIL Steve

1997 «Le traîneau à chiens sur la Côte-Nord : une esquisse », La revue d'histoire de la Côte-Nord, 23, pp. 25-26.

FERLAND Jean-Baptiste A.

1877 Louis Gamache. Le Labrador : opuscules, A. Côté, Québec [1859].

FRIEDMAN Jonathan

2009 «L'indigénéité : remarques à propos d'une variable historique », in Natacha Gagné, Thibault Martin et Marie Salaün (éd.), Autochtonies. Vues de France et du Québec, Presses de l'Université Laval, Québec, pp. 33-57.

Gregory John U.

1886 En racontant : récits et voyages en Floride, au Labrador et sur le fleuve Saint-Laurent, Typographie de C. Darveau, Québec.

HAwkes Edward W.

1916 The Labrador Eskimo, Geological Survey of Canada, coll. « Memoir »91, Ottawa.

Hind Henry Y.

1863 Explorations in the interior of the Labrador peninsula, the country of the Montagnais and Nasquapee Indians, vol. 2, Longman Green, Londres.

HuARD Victor Alphonse

1897 Labrador et Anticosti, Beauchemin, Montréal.

JUNEK Oscar W.

1937 Isolated communities. A study of a Labrador fishing village, American Book Company, New York.

KENNEDY John C.

1995 People of bays and headlands, University of Toronto Press, Toronto.

1996a Labrador village, Waveland Press, Prospect Heights.

1996 b "Our heritage, our identity". The case of the Labrador Metis association », Acta Borealia, 13 (1), pp. 23-34.

LABRÈCHE Yves et John C. KENNEDY

2007 «Héritage culturel des Métis du Labrador central», Recherches amérindiennes au Québec, 37 (2-3), pp. 43-60.

Martijn Charles A.

1980 «La présence inuit sur la Côte-Nord du Golfe St-Laurent à l'époque historique », Études/Inuit/Studies, 4 (1-2), pp. 105-125. 
RoussEAU Louis-Pascal et Étienne RIVARD

2007 "Métissitude : l'ethnogenèse métisse en amont et en aval de Powley », Recherches amérindiennes au Québec, 37 (2-3), pp. 3-6.

RYAn Donald W. S.

1990 Legends of Newfoundland and Labrador, Jesperson Press, St. John's.

SALADIN D’ANGLURE Bernard

1978 La parole changée en pierre : vie et æuvre de Davidialuk Alasuaq, artiste inuit du Québec arctique, Ministère des Affaires culturelles, Québec.

SCHNEIDER Lucien

1970 Dictionnaire français-esquimau du parler de l'Ungava, Presses de l'Université Laval, Québec.

SPENCER Robert F.

1959 The North Alaskan Eskimo. A study in ecology and society, Bureau of American Ethnology, coll. «Bulletin » 171, Washington.

STEARns Winfrid A.

1884 Labrador. A sketch of its people, its industries and its natural history, Lee and Shepard, Boston.

TAYLOR J. Garth

1974 Labrador Eskimo settlements of the early Contact period, National Museum of Man, coll. «Publications in Ethnology » 9, Ottawa.

Tremblay Marc-Adélard, Paul Charest et Yvan Breton

1969 Les changements socio-culturels à Saint-Augustin : contribution à l'étude des isolats de la Côte-Nord du Saint-Laurent, Presses de l'Université Laval, Québec.

TRUDEL François

1980 "Les relations entre les Français et les Inuit au Labrador méridional, 1660-1760 », Études/Inuit/Studies, 4 (1-2), pp. 135-145.

TURNER Lucien M.

1979 Indiens et Esquimaux du Québec, Desclez, Montréal [1894].

VoORT Hein van der

1994 "Eskimo Pidgin », in Jacques Arends, Pieter Muysken et Norval Smith (éd.), Pidgins and Creoles. An introduction, John Benjamins Publishing Co., Amsterdam, pp. 137-151.

ZiMMERLY David W.

1975 Cain's land revisited. Culture change in Central Labrador, 1775-1972, Institute of Social and Economic Research, coll. «Newfoundland Social and Economic Studies » 16, Memorial University of Newfoundland, St. John's. 